\title{
Early Rehabilitation Model Shows Positive Effects on Neural Degeneration and Recovery from Neuromotor Deficits Following Traumatic Brain Injury
}

\author{
M. LIPPERT-GRÜNER ${ }^{1}$, M. MAEGELE ${ }^{2}$, J. POKORNÝ ${ }^{3}$, D. N. ANGELOV ${ }^{4}$, \\ O. ŚVESTKOVÁ ${ }^{5}$, M. WITTNER ${ }^{3}$, S. TROJAN ${ }^{3}$
}

${ }^{1}$ Department of Neurosurgery, Cologne University Hospital, Germany, ${ }^{2}$ Department of Surgery, Cologne Merheim, Germany, ${ }^{3}$ Institute of Physiology, Charles University, Prague, Czech Republic, ${ }^{4}$ Institute of Anatomy, Cologne University, Germany, ${ }^{5}$ Department of Rehabilitation, University Hospital, Prague, Czech Republic

Received date February 26, 2006

Accepted date June 19, 2006

On-line available June 22, 2006

\begin{abstract}
Summary
This study used an experimental early rehabilitation model combining an enriched environment, multisensory (visual, acoustic and olfactory) stimulation and motor training after traumatic brain injury (via fluid-percussion model) to simulate early multisensory rehabilitation. This therapy will be used by brain injured patients to improve neural plasticity and to restore brain integration functions. Motor dysfunction was evaluated using a composite neuroscore test. Direct structural effects of traumatic brain injury were examined using Fluoro-Jade staining, which allows identification of degenerating neural cell bodies and processes. Animals in the rehabilitation model group performed significantly better when tested for neuromotor function than the animals in standard housing in the 7-day and 15-day interval after injury ( $7 \mathrm{~d}: \mathrm{p}=0.005 ; 15 \mathrm{~d}: \mathrm{p}<0.05)$. Statistical analysis revealed significantly lower numbers of Fluoro-Jade positive cells (degenerating neurons) in the rehabilitation model group ( $\mathrm{n}=5$ : mean 13.4) compared to the standard housing group $(\mathrm{n}=6$ : mean 123.8) $(\mathrm{p}<0.005)$. It appears that the housing of animals in the rehabilitation model led to a clear functional increase in neuromotor functions and to reduced neural loss compared with the animal group in standard housing.
\end{abstract}

Key words

Traumatic brain injury $\bullet$ Rehabilitation $\bullet$ Motor dysfunction $\bullet$ Neural loss

\section{Introduction}

Disturbances in neuromotor activity are among the most common defects after traumatic brain damage (Lippert-Grüner and Terhaag 2000, Lippert-Grüner et al. 2002). Especially in patients in the initial phase after heavy skull-brain trauma, marked spastic conditions with motor paralyses of various degrees of severity, accompanied by coordinative disturbances of the trunk, head or extremities, are frequently described. The main priority of rehabilitation therapy is to attempt to restart disturbed motor activity (Ostendorf and Wolf 1981). The 
sooner the active movement in the paretic extremity is initiated, the easier the control of the physiological movements will be restored. It is, however, worth mentioning that the concepts of the therapy based on the motor activity have advanced over the last years. As late as 1970's, the emphasis has been concentrated on purely motor-oriented training programs. However, the tendency over the last few years has been to emphasize the priority of therapies that use experimentally gained knowledge on cerebral re-organization and plasticity, as well as work based on neurophysiology. Moreover, it has increasingly been realized that, in addition to exercising motor functions, a decisive role may also be played by sensory promotion of the renewal of motor functions. For these reasons, prevailing therapeutic schools (Bobath concept, Affolter concept) operate in a very strongly observationoriented way, and selectively integrate sensory impulses (tactile, optical) into the therapy of motor disturbances. A special role is played by motor activities in which patients are faced, in an observation-stimulating way, with specific everyday movements to which they had been familiar when they were still in good health.

That observation encouragement has a positive influence on rebuilding functional deficits after 'acquired' brain damage has been known since numerous investigations were carried out in a multisensory-enriched environment (Artola et al. 2006, Brenes Saenz et al. 2006, Grabowski et al. 1995, Ohlsson and Johansson 1995, Johansson and Ohlsson 1996). Further experiments may prove that motor training has neuroprotective effects on the survival of damaged neurons, as well as positive effects on the recovery of neuromotor functions (Greenough and Chang 1988, Black et al. 1990, Keller et al. 1992, Nygren and Wieloch 2005). A comparison of the effectiveness of enriched environment, physical exercise and training on structural and/or functional assessments of recovery shows that training/learning is generally more effective than physical exercise and that an enriched environment is the most powerful therapy of the three (Will et al. 2004).

This fundamental information is vital for the development of new strategies in rehabilitation therapy. We assume that the combination of multisensory stimulation in an enriched environment and motor training/learning leads to the optimum recovery of the neuromotor functions and the reduction of neuronal loss.

It has not yet been possible to establish a model of early multisensory rehabilitation. This study has used an experimental early rehabilitation model combining an enriched environment, multisensory (visual, acoustic and olfactory) stimulation and motor training/learning after traumatic brain injury to simulate early multisensory rehabilitation therapy used by brain-injured patients to improve neural plasticity, and to restore brain integration functions (Lippert-Grüner and Terhaag 2000, LippertGrüner et al. 2002).

\section{Material}

Young adult (3-month-old) male SpragueDawley rats (300-350 g) were housed in individual cages for a minimum of one week prior to any procedure. Following their adaptation, animals were randomly assigned to one of two experimental groups. Each group consisted of 8 rats (six with brain injury, two were shamoperated).

Group 1: six rats received a lateral fluid percussion (LFP) lesion and were kept together with two sham-operated animals for 15 days under standard housing ( $\mathrm{SH}$ ) conditions in individual cages without stimulation.

Group 2: six rats underwent LFP and were kept together with two sham-operated animals for the following 5 days in the early rehabilitation model including complex enriched environment with multimodal stimuli as described below.

In both environments food and water were constantly available. All animals were kept at a constant temperature $\left(22^{\circ} \mathrm{C}\right)$ in a 12-hour light/dark cycle, with lights on at 7 a.m. All experimental procedures and testing were performed during daylight hours. All experimental procedures conformed to the guidelines of Cologne University and the state's animal protection and ethics committee. All efforts were made to minimize animal discomfort and to reduce the total number of animals used.

\section{Surgery}

The lateral fluid-percussion (LFP) brain injury model is one of the most widely used and well characterized models of experimental traumatic brain injury (McIntosh et al. 1987, 1989). In brief, animals were anesthetized with sodium pentobarbital $(60 \mathrm{mg} / \mathrm{kg}$, intra peritoneal), placed in a stereotaxic frame, and the scalp and temporal muscle were reflected (Fig. 1). A hollow female Luer-lock fitting was rigidly fixed with dental cement to a $4.8 \mathrm{~mm}$ craniotomy centered between bregma and lambda and $2.5 \mathrm{~mm}$ lateral to the sagittal 


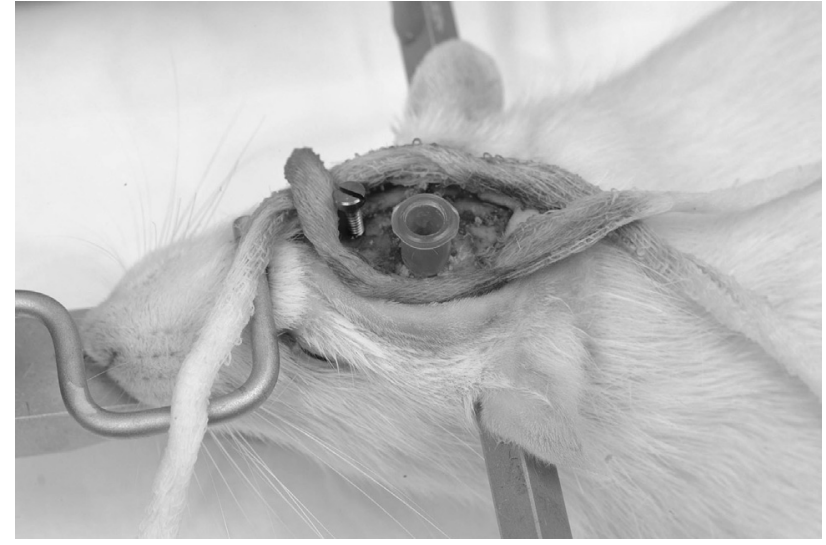

Fig. 1. Surgery in the stereotaxic frame.

sinus, keeping the dura mater intact.

The fluid-percussion device consisted of a plexiglass cylinder filled with isotonic saline. One end of the cylinder was connected to a metal joint terminating in a male Luer-lock fitting. Prior to the induction of trauma, the male Luer-lock was connected to the female Luerlock anchored in the rat's skull, creating a closed system filled with isotonic saline in contact with the dura (Fig. 2). The trauma was induced by the fall of a metal pendulum against a piston inducing a pulse of increased intracranial pressure of 21-23 ms duration through rapid injection of saline into the closed cranial cavity, resulting in a brief displacement and deformation of neural tissue, a subdural hematoma, and a cortical contusion in the frontoparietal cortex (Maegele et al. 2005).

The pressure pulse was measured extracranially by a transducer (Gould) housed in the injury device and recorded on a computer oscilloscope emulation program (RC Electronics). Following moderate injury (2.1 atm), the incision was closed with interrupted 4.0 silk sutures, and the animals were placed onto a heated pad to maintain body temperature for $1 \mathrm{~h}$ after surgery. All animals were monitored for at least $6 \mathrm{~h}$ postsurgery, then daily. Sham-operated animals underwent the surgical procedures described above, but were not subjected to brain injury (Maegele et al. 2005).

\section{Early rehabilitation model}

Twenty-four hours after the trauma, the animals were returned to individual cages without stimulation (standard housing SH; Group 1) or put in specially designed cages (3 larger cages $610 \mathrm{~cm} \times 435 \mathrm{~cm} \times$ $215 \mathrm{~cm}$ connected via tunnels; Group 2). The special cages had enriched environments (consisting of horizontal and inclining platforms and various toys) and the rats received additional multimodal sensory stimulation (standardized protocol of sensory stimulation adopted from Inglis and Fibiger (1995) and motor training on a rotating rod).

Sensory stimulation: To introduce auditory, visual and olfactory stimuli, a self-built auditory and visual stimulation apparatus was installed just above the enriched environment (EE) cages. It produced the following 3 series of standardized auditory and visual stimuli during the night (dark cycle): (a) auditory (20 min): an intermittent buzzing $(80 \mathrm{~dB}), 30 \mathrm{~s}$ on, $30 \mathrm{~s}$ off; (b) pause (20 min), (c) visual (20 min): a flashing white light $(60 \mathrm{~W}, 1 \mathrm{~Hz}), 30 \mathrm{~s}$ on, $30 \mathrm{~s}$ off, (d) pause (20 min). Olfactory stimulation was provided by lowering perfumed q-tips into the cages twice daily at the transition periods from light to dark and dark to light using a standardized neurological olfactory test battery including the following perfumes: aniseed, bitter almond, mint, vanilla, and rose oil (Fig. 3).

Motor stimulation: For motor stimulation, animals were trained to run on a commercially obtained rotarod apparatus for one session a day (15 minutes) on five consecutive days.

\section{Neurological evaluation}

Motor function was evaluated using a composite neuroscore test (Okiyama et al. 1992, Sinson et al. 1995, McIntosh et al. 1989). The animals were tested by an investigator blind to the injury status of each animal. Animals were scored from 0 (severely impaired) to 4 (normal strength and function) for each of the following modalities:

- forelimb flexion during suspension by the tail;

- hindlimb flexion with the forelimbs remaining on a flat surface as the hindlimbs were lifted up and back by the tail;

- ability to resist lateral pulsion;

- ability to stand on an inclined plane in the left, right and vertical position. (inclined plane scoring (0-4) was determined by the animal's ability to stand at an angle of up to 45 degrees $\left(4=45^{\circ} ; 3=42.5^{\circ}\right.$; $2=40^{\circ} ; 1=37.5^{\circ} ; 0<37.5^{\circ}$ )

A composite neurological motor score (0-28) was calculated for each animal from the sum of the individual test scores. The baseline of motor score had been measured $24 \mathrm{~h}$ prior to injury. Recovering of function was evaluated at $24 \mathrm{~h}, 7$ and 15 days after the trauma. 


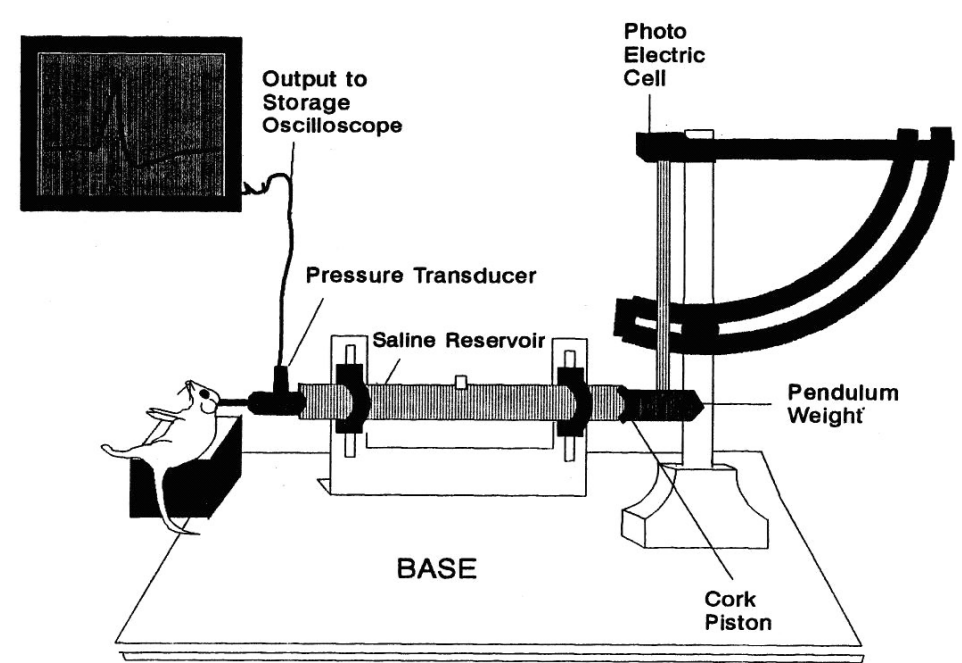

Fluid Percussion Device

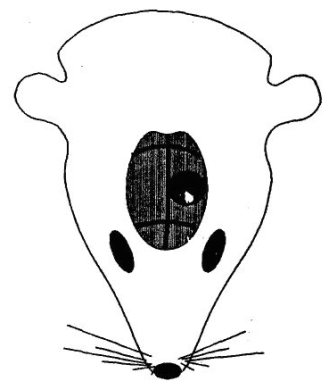

Craniotomy

Fig. 2. Fluid-percussion model.
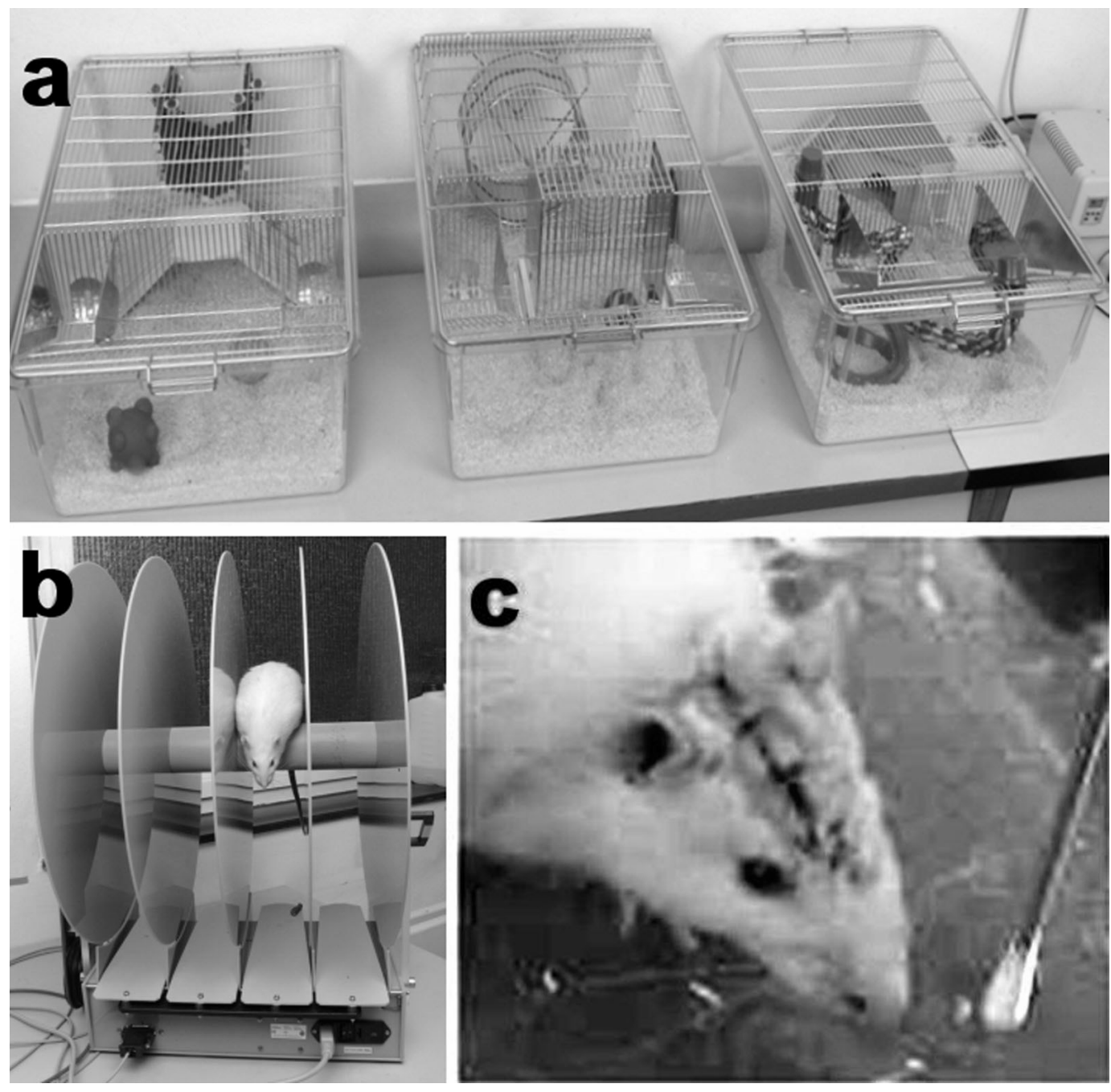

Fig. 3. Multi-Modal Early-Onset Stimulation (MEOS) in Enriched Environment (EE). For MEOS in EE, animals were placed in specifically designed wide-bodied cages connected via tunnels, with various types of toys and bedding (a) along with motor (b), olfactory (c) and auditory stimulation. 


\section{Tissue preparation}

At 15 days post injury, the animals were transcardially perfused with $0.9 \% \mathrm{NaCl}$ in distilled water for $60 \mathrm{~s}$ followed by a fixation with $4 \%$ paraformaldehyde in $0.1 \mathrm{M}$ phosphate buffer ( $\mathrm{pH}$ 7.4) under deep ether anesthesia.

We performed Fluoro-Jade staining in one transversal (coronal) section through the brain. After removal and postfixation of the brain (same fixative for $24 \mathrm{~h}$ at $4{ }^{\circ} \mathrm{C}$ ) the coronal slice with the lesion was dissected free. The rostral border of each brain slice was defined by the clearly visible demarcation of the infundibular recess of the third ventricle (bregma $2.3 \mathrm{~mm}$ ). The other cut was made approximately $5 \mathrm{~mm}$ dorsally. Demarcation of the lesioned side by a canuleperforation in the caudoputamen followed. The cryoprotected (in $30 \%$ sucrose in $0.1 \mathrm{M}$ phosphate buffer, $\mathrm{pH}$ 7.4) slice was serially sectioned in the coronal plane in $25 \mu \mathrm{m}$ thick sections, which yielded approximately 200 sections from each brain. Two neighboring sections were mounted on Superfrost/Plus slides (Carl Roth GmbH \& Co. KG, Karlsruhe, Germany, Cat. Nr. H867.1).

\section{Fluoro-Jade staining}

Direct structural effects of traumatic brain injury were examined using Fluoro-Jade staining. Fluoro-Jade is an acidic dye that exhibits a marked affinity for both the degenerating neural cell body and its processes. This method makes it possible to determine the extent of injury on the basis of neural loss.

Hoechst is a DNA specific dye which allows "Nissl staining" to be modified for fluorescent microscopy. It can show the structure of "normal" cell nuclei and thus allow the approximate differentiation of neurons and glia cells and to see the stratification of the cortex. It is also useful in other neuroanatomical observations. Hoechst staining also reveals pathological signs, e.g. the development of pyknosis or nucleolar fragmentation.

Coronal sections $40 \mu \mathrm{m}$ thick were cut on a vibratome and mounted onto gelatinized slides. For processing for Fluoro-Jade staining, slides within the region of the lesion were placed in staining racks (one slide per slot for even staining) and immersed in $100 \%$ ethanol for $3 \mathrm{~min}$ followed by $70 \%$ ethanol for one minute, rinsed in distilled water, then incubated with $0.06 \%$ potassium permanganate for $15 \mathrm{~min}$ to decrease background staining. Slides were rinsed with distilled water three times. Staining proceeded in a dim place by immersing slides into $0.001 \%$ Fluoro-Jade B solution (Histo-Chem Inc., Jefferson, AR, USA) for $30 \mathrm{~min}$ with occasional gentle shaking. Subsequently, these slides were rinsed in distilled water for one minute three times. Slides were then immersed in $0.01 \%$ Hoechst staining solution (bisbenzimide, Hoechst No 33258, Sigma) for 10 min, rinsed again with distilled water and allowed to air dry at room temperature. Slides were coverslipped with DPX neutral mounting medium and stored at $12^{\circ} \mathrm{C}$ to preserve histofluorescent intensity until they were examined using an epi-illumination fluorescence microscope (Olympus Provis AX70) with blue (450-490 $\mathrm{nm}$ ) excitation light. The slides were examined by an investigator blind to the injury status of each animal.

\section{Statistical analysis}

For statistical analysis, the $t$-test and SPSS software were used.

\section{Results}

\section{Composite neuroscore tests}

These tests indicated better performance in EE+MEOS (Multi-Modal Early-Onset Stimulation in Enriched Environment) rats: $24 \mathrm{~h}$ before injury, no differences were observed between sham-operated animals, all animals achieved test results of 28 points. 24 hours after brain injury, animals exhibited high levels of neurological deficits when compared with the shamoperated controls $(p<0.001)$. There were no significant differences between the composite neuroscores of both injured groups at $24 \mathrm{~h}$ post-injury. This shows that the levels of neuromotor deficits in both groups were comparable.

However, injured animals with early rehabilitation model performed significantly better than rats in standard housing condition when tested for neuromotor function on the 7 th $(p<0.005)$ and 15 th $(p<0.05)$ day post injury (Fig. 4), indicating superior neurofunctional recovery (Table 2).

Injured animals in standard housing began to recover a little within the first week post-injury, but the recovery did not markedly continue over time. More importantly, the composite neuroscores in both injured groups remained much lower than in the sham-operated controls. 


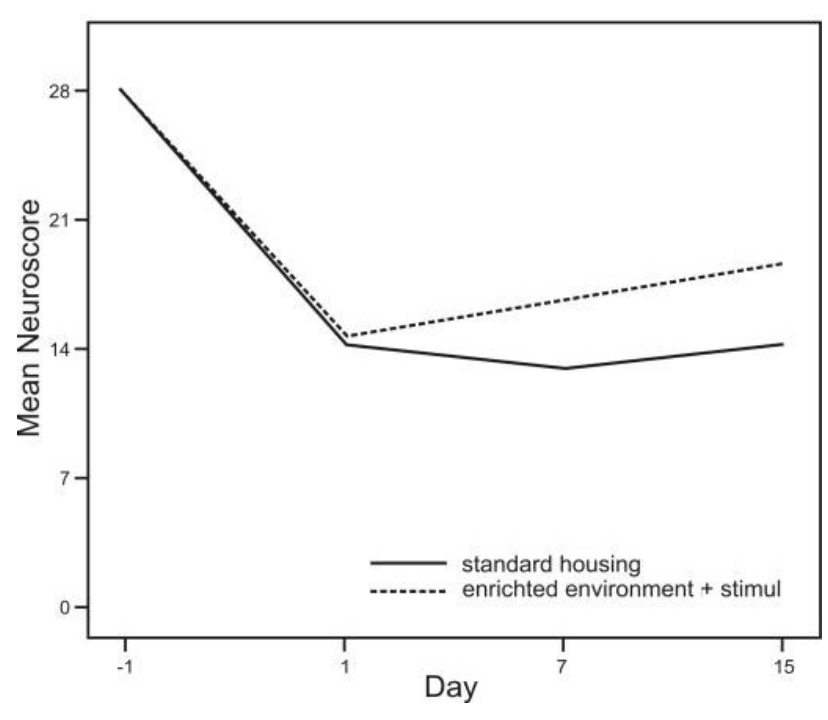

Fig. 4. Composite Neuroscore reveals superior neuromotor function in the early rehabilitation model animals versus animals in standard housing at 7 and 15 days post trauma.

\section{Structural changes}

Degenerating cells in the lesion (Fluoro-Jade positive cells) were studied in 11 animals (6 animals from the standard housing group and 5 animals from the early rehabilitation group). One brain from group 2 could not be used because of unsuccessful perfusion. Tables 1 and 2 give the average number of Fluoro-Jade positive cells in individual equidistant slides obtained from the region of lesion. No Fluoro-Jade positive cells were found in shamoperated animals in either group. Typical micrographs of lesioned regions are shown in Figures 5, 6 and 7.

Statistical analysis $(t$-test) revealed significantly lower numbers of degenerating neurons (Fluoro-Jade positive cells) in animals of the rehabilitation model $(\mathrm{n}=5$ : mean 13.4) compared to rats in standard housing conditions $(\mathrm{n}=6$ : mean 123.8$)(\mathrm{p}<0.005)$.

\section{Discussion}

The effects of motor stimulation on functional rehabilitation after skull-brain damage are currently studied in experimental animal models. These experiments are mainly concerned with neurotrophin expression, and have shown that motor exercise (voluntary running) can positively influence the expression of brain-derived neurotrophic factor (BDNF) (Neeper et al. 1996). Motor activity has been proposed as one factor, which can reduce age-related decline in memory and cognition (Dustman et al. 1984). In addition, experiments in rats have shown that motor training before experimental ischemic or traumatic brain damage leads to
Table 1. Number of Fluoro-Jade positive cells (standard housing, $\mathrm{n}=6)$.

\begin{tabular}{ll}
\hline $\begin{array}{l}\text { Standard housing } \\
\text { (Group 1) }\end{array}$ & $\begin{array}{l}\text { Number of Fluoro-Jade } \\
\text { positive cells }\end{array}$ \\
\hline Animal 1 & 59 \\
Animal 2 & 122 \\
Animal 3 & 250 \\
Animal 4 & 183 \\
Animal 5 & 78 \\
Animal 6 & 51 \\
Sham 1 & 0 \\
Sham 2 & 0 \\
\hline
\end{tabular}

Table 2. Number of Fluoro-Jade positive cells (early rehabilitation model, $\mathrm{n}=5$ ).

\section{Early rehabilitation Number of Fluoro-Jade model (Group 2) positive cells}

\begin{tabular}{ll}
\hline Animal 1 & 0 \\
Animal 2 & 13 \\
Animal 3 & 54 \\
Animal 4 & 0 \\
Animal 5 & 0 \\
Sham 1 & 0 \\
Sham 2 & 0 \\
\hline
\end{tabular}

a decrease in the mortality rate (Stummer et al. 1994). The conclusion can be drawn that the increased expression of neurotrophic factors, brought about by motor training, has a neuroprotective influence on the damage of the neurons as well as on their survival (Oliff et al. 1998). These findings suggest that motor activity is an important behavioral parameter, which, in the process of neural stimulation, is able to exert a positive influence not only on the motor outcome but also on the recovery of cognitive functions, as well as on the vulnerability of the brain with regards to the damage incurred (Dua and Hargreaves 1992, Dustman et al. 1984, Irvine et al. 2006, Rejeski et al. 1992, Oliff et al. 1998). Thus motor training, as in treadmill exercises, reduced the infarction volume in experimentally induced ischemia (Greenough and Chang 1988, Black et al. 1990, Keller et al. 1992). Apart from the positive effects of training on neuroprotection, neuroplasticity and angiogenesis, it has also been shown that the signs of neurodegenerative processes such as apoptosis, edema or the release of 


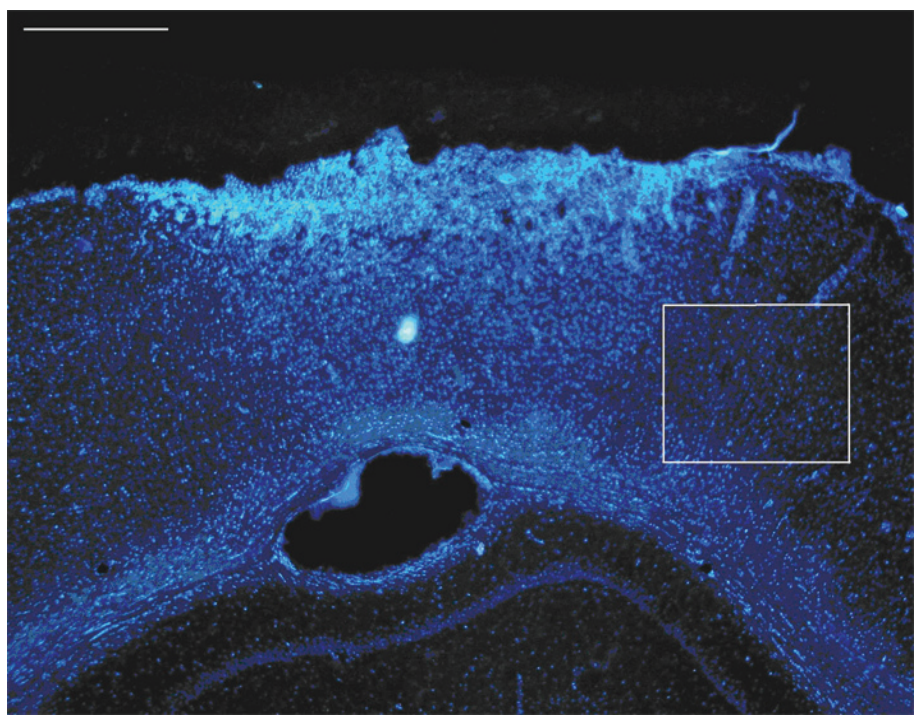

Fig. 5. Traumatic brain injury. Frontal section through the cortex. Hoechst (bisbenzimide) staining. Delineated dectangular area (original size $640 \mu \mathrm{m} \times 520 \mu \mathrm{m}$ ) of the lesion margin is shown with higher magnification in Figs. 6 and 7. A scale bar indicates $500 \mu \mathrm{m}$.

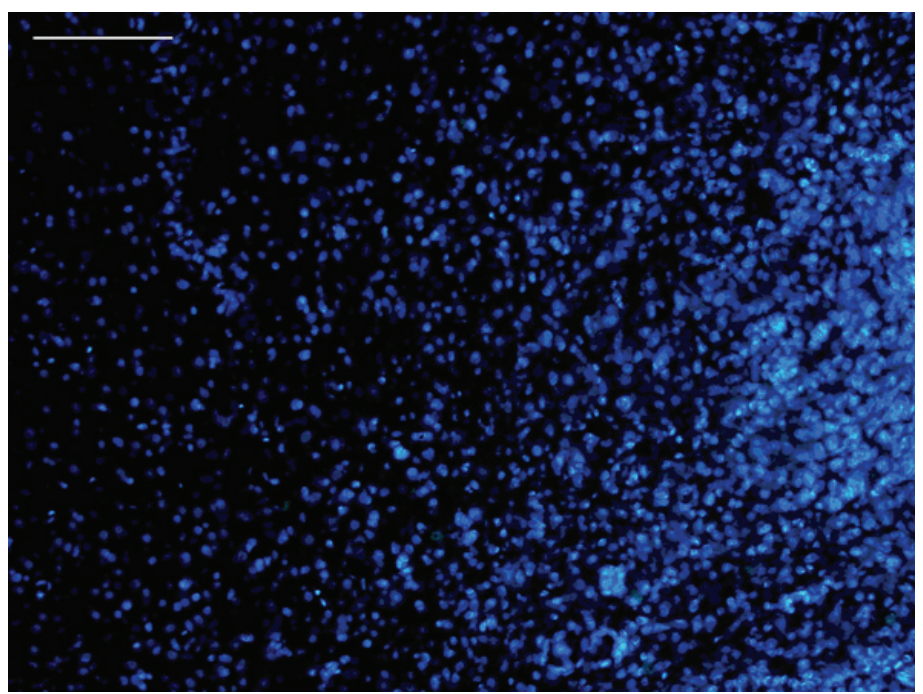

Fig. 6. Lesion margin (penumbra). Hoechst (bisbenzimide) staining. A scale bar indicates $100 \mu \mathrm{m}$.

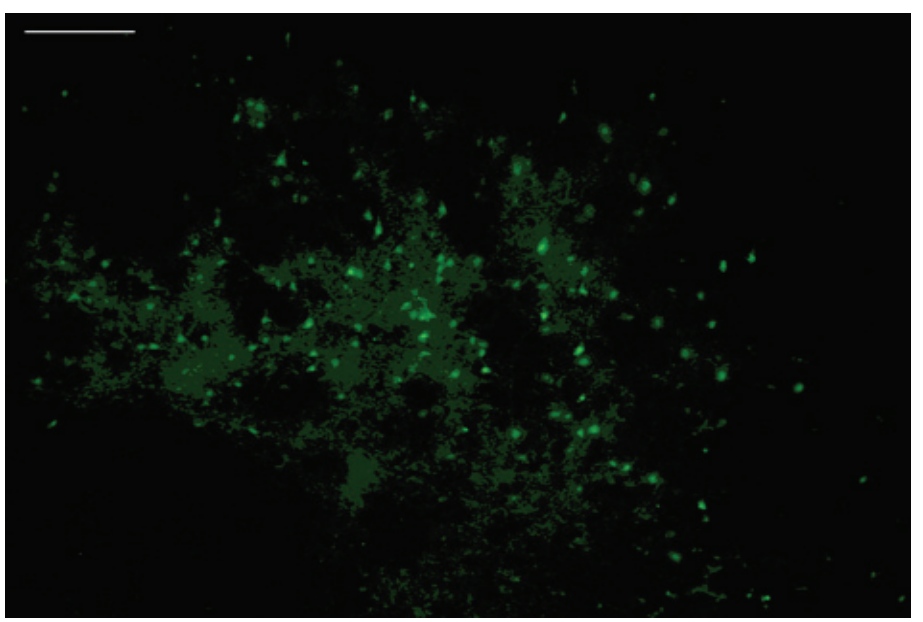

Fig. 7. Lesion margin (penumbra), identical region to Fig. 6. Degenerating neurons (Fluoro-Jade B positive cells - green) are located only within the margin of the lesion. A scale bar indicates $100 \mu \mathrm{m}$.

neurite growth inhibiting molecules are reduced (Mattson et al. 2000). The aim of these studies was to improve our knowledge of the possibilities of reducing brain damage and secondary degenerative processes, as well as the neural regeneration and compensatory mechanism.

Forced motor activity during the first week after surgery can amplify the extent of cortical ischemic or traumatic injury and could have negative results on 
functional recovery (Bland et al. 2000, 2001, Humm et al. 1999, Risedal et al. 1999).

In addition to the selective training of motor functions, many studies appear to show that multisensory stimulation in the form of an enriched environment has a positive effect on the recovery of both motor and cognitive functions (Gentile et al. 1987, Grabowski et al. 1995, Ohlsson and Johansson 1995, Johansson and Ohlsson 1996, Zhu et al. 2006) as well as on cerebral reorganisation (Benefiel et al. 2005, Bennett et al. 1964, Greenough and Volkmar 1973, Johansson and Belichenko 2002, Johansson 2004, Kolb 1995, Rosenzweig 1966, Young et al. 1999, Zeng et al. 2000, Zhao et al. 2001).

It had not been possible to establish a standardized model of early rehabilitation in the form of an enriched environment in combination with multisensory stimulation and training of motor functions during recent years.

This study was designed to determine whether exposure to the multisensory early rehabilitation model after moderate traumatic brain injury in rats would promote the recovery of neuromotor functions and prevent neuronal loss in comparison with housing under standard conditions. Neuromotor function assessed by Neuroscore was markedly reduced in both injured groups at $24 \mathrm{~h}$ post injury. However, animals in the rehabilitation model group performed significantly better when tested for neuromotor function than animals in standard housing in the 7-day and 15-day interval $(7 \mathrm{~d}: \mathrm{p}<0.005 ; 15 \mathrm{~d}$ : $\mathrm{p}<0.05$ ). The exact effects of individual components of the rehabilitation model are not yet known.

Statistical analysis revealed significantly lower numbers of Fluoro-Jade positive cells (degenerating neurons) in the rehabilitation model group ( $\mathrm{n}=5$ : mean 13.4) compared to the standard housing group ( $n=6$ : mean 123.8) $(\mathrm{p}<0.005)$.

The results of our study show that exposing animals to the rehabilitation model including especially multisensory stimulation and five-day rotarod training led to a clear functional increase in neuromotor functions and reduced neural loss, when compared with the animal group in the standard housing. The rehabilitation model proposed here as a model for early multisensory rehabilitation in the early phase of illness should be helpful in developing new therapies that are partially based on knowledge gained from animal experiments. The negative effects of excessive motor activity, in the form of increased brain damage, can be explained in terms of the reduced ability of patients suffering from brain damage to cope with strain. This need not be interpreted as a negative consequence of early motor stimulation (Kozlowski et al. 1996, Bland et al. 2000, 2001, Humm et al. 1998, 1999, Risedal et al. 1999).

For successful clinical use, the necessity to establish frequency and intensity of rehabilitative treatment continues to be of crucial importance. In the future it will be essential to utilize the fundamentals of neurophysiology in planning physiotherapeutic treatments. Future research should provide information about which physiological mechanisms can be activated and what neural structures should be taken into account to make rehabilitation treatment really successful.

\section{Acknowledgement}

This study was supported in part by Charles University Grant Agency grant Nr. 25/2005 and grant Nr. MSM 0021620816.

\section{References}

ARTOLA A, VON FRIJTAG JC, FERMONT PC, GISPEN WH, SCHRAMA LH, KAMAL A, SPRUIJT BM: Longlasting modulation of the induction of LTD and LTP in rat hippocampal CA1 by behavioural stress and environmental enrichment. Eur J Neurosci 23: 261-272, 2006.

BENEFIEL AC, DONG WK, GREENOUGH WT: Mandatory "enriched" housing of laboratory animals: the need for evidence-based evaluation. ILAR J 46: 95-105, 2005.

BENNETT EL, DIAMOND MC, KRECH D, ROSENZWEIG MR: Chemical and anatomical plasticity of brain. Science 146: 610-619, 1964.

BLACK JE, ISAACS KR, ANDERSON BJ, ALCANTARA AA, GREENOUGH WR: Learning causes synaptogenesis, whereas motor activity causes angiogenesis, in cerebellar cortex of adult rats. Proc Natl Acad Sci USA 87: 5568-5572, 1990. 
BLAND ST, SCHALLERT T, STRONG R, ARONOWSKI J, GROTLA JC, FEENEY DM: Early exclusive use of the affected forelimb after moderate transient focal ischemia in rats: Functional and anatomic outcome. Stroke 31: 1144-1152, 2000.

BLAND ST, PILLAI RN, ARONOWSKI J, GROTTA JC, SCHALLERT T: Early overuse and disuse of the affected forelimb after moderately severe intraluminal suture occlusion of the middle cerebral artery in rats. Behav Brain Res 126: 33-41, 2001.

BRENES SAENZ JC, VILLAGRA OR, FORNAGUERA TRIAS J: Factor analysis of Forced Swimming test, Sucrose Preference test and Open Field Test on enriched, social and isolated rats. Behav Brain Res 169: 57-65, 2006.

DUA J, HARGREAVES L: Effect of aerobic exercise on negative affect, positive affect, stress, and depression. Percept Mot Skills 75: 355-361, 1992.

DUSTMAN RE; RUHLING RO; RUSSELL EM; SHEARER DE; BONEKAT HW; SHIGEOKA JW; WOOD JS; BRADFORD DC: Aerobic exercise training and improved neuropsychological function of older individuals. Neurobiol Aging 5: 35-42, 1984.

GENTILE AM, BEHESHTI Z, HELD M J: Enrichment versus exercise effects on motor impairments following cortical removals in rats. Behav Neural Biol 47: 321-332, 1987.

GRABOWSKI MM, SORENSEN JC, MATTSSON B, ZIMMER J, JOHANSSON BB: Influence of an enriched environment and cortical grafting on functional outcome in brain infarcts of adult rats. Exp Neurol 133: 96-102, 1995.

GREENOUGH WT, CHANG FL: Dendritic pattern formation involves both oriented regression and oriented growth in the barrels of mouse somatosensory cortex. Brain Res 471: 148-152, 1988.

GREENOUGH WT, VOLKMAR FR: Pattern of dendritic branching in occipital cortex of rats reared in complex environment. Exp Neurol 40: 491-504, 1973.

HUMM JL, KOZLOWSKI DA, JAMES DC, GOTTS JE, SCHALLERT T: Use-dependent exacerbation of brain damage occurs during an early post-lesion vulnerable period. Brain Res 783: 286-292, 1998.

HUMM JL, KOZLOWSKI DA, BLAND ST, JAMES DC, SCHALLERT T: Progressive expansion of brain injury by extreme behavioral pressure: Is glutamate involved? Exp Neurol 157: 349-358, 1999.

INGLIS FM, FIBIGER HC: Increases in hippocampal and frontal cortical acetylcholine release associated with presentation of sensory stimuli. Neuroscience 66: 81-86, 1995.

IRVINE GL, LOGAN B, ECKERT M, ABRAHAM WC: Enriched environment exposure regulates excitability, synaptic transmission, and LTP in the dentate gyrus of freely moving rats. Hippocampus 16: 149-160, 2006.

JOHANSSON BB: Functional and cellular effects of environmental enrichment after experimental brain infarcts. Res Neurol Neurosci 22: 163-174, 2004.

JOHANSSON BB, BELICHENKO PV: Neuronal plasticity and dendritic spines: effect of environmental enrichment on intact and postischemic rat brain. J Cereb Blood Flow Metab 22: 89-96, 2002.

JOHANSSON BB, OHLSSON AL: Environment, social interaction and physical activity as determinants of functional outcome after cerebral infarction in the rat. Exp Neurol 139: 322-327, 1996.

KELLER A, ARISSIAN K, ASANUMA H: Synaptic proliferation in the motor cortex of adult cats after long-term thalamic stimulation. J Neurophys 68: 295-308, 1992.

KOLB B: Brain Plasticity and Behavior. Lawrence Erlbaum, Hillsdale, NJ, 1995.

KOZLOWSKI DA, JAMES DC, SCHALLERT T: Use-dependent exaggeration of neuronal injury after unilateral sensorimotor cortex lesions. J Neurosci 16: 4776-4786, 1996.

LIPPERT-GRÜNER M, TERHAAG D: Multimodal early onset stimulation (MEOS) in rehabilitation after brain injury. Brain Injury 14: 585-594, 2000.

LIPPERT-GRÜNER M, WEDEKIND C, ERNESTUS RI, KLUG N: Early rehabilitative concepts in therapy of the comatose brain injured patients. Acta Neurochir Suppl 79: 21-23, 2002.

MAEGELE M, LIPPERT-GRUENER M, ESTER-BODE TH, GARBE J, BOUILLON B, NEUGEBAUER E, KLUG N, NEISS W, ANGELOV D: Multimodal early onset stimulation combined with enriched environment is associated with reduced CNS scar formation and enhanced reversal of neuromotor dysfunction after traumatic brain injury in rats. Eur J Neurosci 21: 2406-2418, 2005. 
MATTSON MP; CULMSEE C; YU ZF: Apoptotic and antiapoptotic mechanisms in stroke. Cell Tissue Res 301: 173$87,2000$.

MCINTOSH TK, NOBLE L, ANDREWS B, FADEN AI: Traumatic brain injury in the rat: characterization of a midline fluid-percussion model. Central Nerv Syst Trauma 4: 119-134, 1987.

McINTOSH TK, VINK R, NOBLE L, YAMAKAMI I, FERNYAK S, SOARES H, FADEN AL: Traumatic brain injury in the rat: characterization of a lateral fluid-percussion model. Neuroscience 28: 233-244, 1989.

NEEPER SA, GOMEZ-PINILLA F, CHOI J, COTMAN CW: Physical activity increases mRNA for nerve growth factor in rat brain. Brain Res 726: 49-56, 1996.

NYGREN J, WIELOCH T: Enriched environment enhances recovery of motor function after focal ischemia in mice, and downregulates the transcription factor NGFI-A. J Cereb Blood Flow Metab 25: 1625-1633, 2005.

OHLSSON AL, JOHANSSON BB: Environment influences functional outcome of cerebral infarction in rats. Stroke 26: 644-649, 1995.

OKIYAMA K, SMITH DH, THOMAS MJ, MCINTOSH TK: Evaluation of a novel calcium channel blocker, (S)-emopamil, on regional cerebral edema and neurobehavioral function after experimental brain injury. J Neurosurg 77: 607-615, 1992.

OLIFF HS; BERCHTOLD NC; ISACKSON P, COTMAN CW: Exercise-induced regulation of brain-derived neurotrophic factor (BDNF) transcripts in the rat hippocampus. Brain Res Mol Brain Res 61: 147-153, 1998.

OSTENDORF CG, WOLF SL: Effect of forced use of the upper extremity of a hemiplegic patient on changes in function. Phys Ther 61: 1022-1028, 1981.

REJESKI WJ, THOMPSON A, BRUBAKER PH, MILLER HS: Acute exercise: buffering psychosocial stress responses in women. Health Psychol 11: 355-362, 1992.

RISEDAL A, ZENG J, JOHANSSON BB: Early training may exacerbate brain damage after focal brain ischemia in the rat. J Cereb Blood Flow Metab 19: 997-1003, 1999.

ROSENZWEIG MR: Environmental complexity, cerebral change and behavior. Am Psychol 21: 321-332, 1966.

SINSON G, VODDI M, MCINTOSH TK: Nerve growth factor administration attenuates cognitive but not neurobehavioral motor dysfunction or hippocampal cell loss following fluid-percussion brain injury in rats. J Neurochem 65: 2209-2216, 1995.

STUMMER W, WEBER K, TRANMER B, BAETHMANN A, KEMPSKI O: Reduced mortality and brain damage after locomotor activity in gerbil forebrain ischemia. Stroke 25: 1862-1869, 1994.

WILL B, GALANI R, KELCHE C, ROSENZWEIG MR: Recovery from brain injury in animals: relative efficacy of environmental enrichment, physical exercise or formal training (1990-2002). Prog Neurobiol 72: 167-182, 2004.

YOUNG D, LAWLOR PA, LEONE P, DRAGUNOW M, DURING MJ: Environmental enrichment inhibits spontaneous apoptosis, prevents seizures and is neuroprotective. Nat Med 5: 448-453, 1999.

ZENG J, MATTSSON B, SCHULZ MK, JOHANSSON BB, SORENSEN JC: Expression of zinc-positive cells and terminals in fetal neocortical homografts to adult rat depends on lesion type and rearing conditions. Exp Neurol 164: 176-183, 2000.

ZHAO LR, RISEDAL A, WOJCIK A, HEJZLAR J, JOHANSSON BB, KOKAIA Z: Enriched environment influences brain-derived neurotrophic factor levels in rat forebrain after focal stroke. Neurosci Lett 305: 169-172, 2001.

ZHU SW, YEE BK, NYFFELER M, WINBLAD B, FELDON J, MOHAMMED AH: Influence of differential housing on emotional behaviour and neurotrophin levels in mice. Behav Brain Res 169: 10-20, 2006.

\section{Reprint requests}

Marcela Lippert-Grüner, Klinik für Allgemeine Neurochirurgie der Universität zu Köln, Joseph-Stelzmann Str. 9, 50931 Köln, Germany. E-mail: marcela.lippert-gruener@medizin.uni-koeln.de 